\title{
DISTRIBUIÇÃO ESPAÇO-TEMPORAL DOS DESASTRES NATURAIS ASSOCIADOS À DINÂMICA CLIMÁTICA NO ESTADO DO CEARÁ
}

\author{
João Luís Sampaio Olímpio ${ }^{1}$ \\ Maria Elisa Zanella ${ }^{2}$
}

\begin{abstract}
RESUMO: No estado do Ceará é recorrente a materialização de desastres naturais induzidos pela ocorrência de eventos naturais extremos, como as secas e as inundações que, por vezes, motivam a decretação de Situação de Emergência ou Estado de Calamidade Pública. Neste artigo, apresentam-se os desastres naturais citados ocorridos no estado do Ceará, a partir do levantamento das Portarias de reconhecimento de Situação de Desastre emitidas entre os anos de 2003 a 2013 e pela análise da variabilidade pluviométrica da estação chuvosa. Os resultados revelaram quais as porções do estado são mais vulneráveis às adversidades induzidas pela dinâmica climática da região semiárida e sua relação com uma fragilidade natural e com um contexto socioeconômico, cultural, institucional e estrutural presentes nos municípios cearenses. Assim, esta pesquisa visa analisar a distribuição dos desastres naturais e dos danos produzidos na série histórica indicada, gerando informações que podem ser apropriadas pelos tomadores de decisão, com vista à gestão dos riscos de desastres.
\end{abstract}

Palavras-chave: clima; seca; inundação; SIG.

\section{SPACE-TIME DISTRIBUTION OF NATURAL DISASTERS ASSOCIATED TO CLIMATE DYNAMICS IN CEARÁ}

\begin{abstract}
In the state of Ceará it is common to occur the materialization of natural disasters due to the happening of extreme natural events such as droughts and floods, that sometimes motivate the declaration of Emergency Situation and State of Public Calamity. In this article, we present the mentioned natural disasters in the state of Ceará taken from the ordinances of Disaster Situation acknowledgement emitted between the years 2003-2013 and the analysis of rainfall variability of the rainy season. The results revealed that the parts of the state that are more vulnerable to natural adversities because of the semi-arid region's climate dynamics and its relation with a natural frailty and a socioeconomic, cultural, institutional and structural context present in Ceará's counties. So, this research aims to analyze the distribution of natural disasters and of the damage produced in the time historical series indicated, generating information that can be appropriated by decision makers, aiming the disaster risk management.
\end{abstract}

Keywords: climate; drought; flood; GIS.

1. Universidade Federal do Ceará (jluisolimpio@gmail.com).

2. Universidade Federal do Ceará (elizazv@terra.com.br). 


\section{INTRODUÇÃO}

Sociedade e natureza são entidades que desde o princípio mantiveram relações, ora marcadas por conflitos, ora por harmonias. Assim, as diferentes sociedades, em função de suas necessidades e das formas de apropriação dos recursos naturais, consolidaram meios diferenciados de utilizarem as oportunidades presentes nos espaços naturais. Todavia, muitas destas formas de uso do meio natural não estão de acordo com a dinâmica dos ambientes, pondo em risco os indivíduos e os seus bens materiais e imateriais. Tal relação fundamenta a constituição dos desastres naturais.

Neste sentido, os eventos naturais intensos podem se tornarem perigosos às sociedades, desde que estas não tenham meios para enfrentá-los adequadamente, através de ações de gestão dos riscos de desastres, bem como em decorrência das condições socioeconômicas, político-institucionais e culturais frente à dinâmica natural.

A origem dos desastres naturais remete à própria sedentarização do homem. Outrora nômade, o ser humano passa a se fixar em espaços naturais cujas potencialidades permitiam o desenvolvimento de atividades essenciais para as sociedades, principalmente a agricultura (MARCELINO, 2008). Ambientes com solos férteis, agricultáveis e com disponibilidade de recursos hídricos foram utilizados nestas atividades, iniciando a ocupação das planícies fluviais, das vertentes úmidas, das terras de origem vulcânica, entre outras. Todavia, estes espaços também apresentam uma dinâmica natural singular, o que em determinadas situações pode expor a população, provocando danos sociais, econômicos e ambientais.

É a partir da Revolução Industrial que a vulnerabilidade das sociedades ocidentais amplia-se, em decorrência da apropriação de ambientes naturais e rurais pelas populações urbanas, sem o devido reconhecimento das potencialidades e limitações do meio, além da falta de ações do Poder Público e da sociedade civil na gestão do espaço, resultando em impactos durante e após a constituição de eventos naturais intensos.

$\mathrm{Na}$ atualidade, tais eventos, aparentemente, possuem uma frequência e uma intensidade maior. Desta situação, discursos diferenciados são produzidos para justificar as causas dos desastres, como os castigos de Deus, ciclos glaciais, mudanças climáticas e as intervenções humanas na natureza. No entanto, convém ressaltar que atribuir somente à natureza os danos provocados pelos desastres naturais é um equívoco. Esta responsabilidade cabe, sobretudo, as ações dos homens, modificando a dinâmica natural e elevando a vulnerabilidade das sociedades (VEYRET; RICHEMOND, 2007).

Ressalta-se que as noções de riscos, desastres, catástrofes, entre outras, são de ordem humana, pois suas repercussões somente têm importância quando atingem espaços habitados ou de importância econômica/cultural. Deste modo, reconhece-se que a sociedade é um elemento essencial para a solução da problemática ambiental contemporânea (MENDONÇA, 2005).

Neste cenário encontra-se o estado do Ceará. Situado na porção setentrional do Nordeste brasileiro (Figura 01), este território apresenta um conjunto de componentes que permitem à formação de uma predisposição do meio natural à ocorrência de eventos naturais perigosos, principalmente os originados dos desvios positivos e negativos da pluviosidade e de forma pontual pelos processos erosivos exacerbados, agravados pelas intervenções antropogênicas em ambientes muito vulneráveis. 


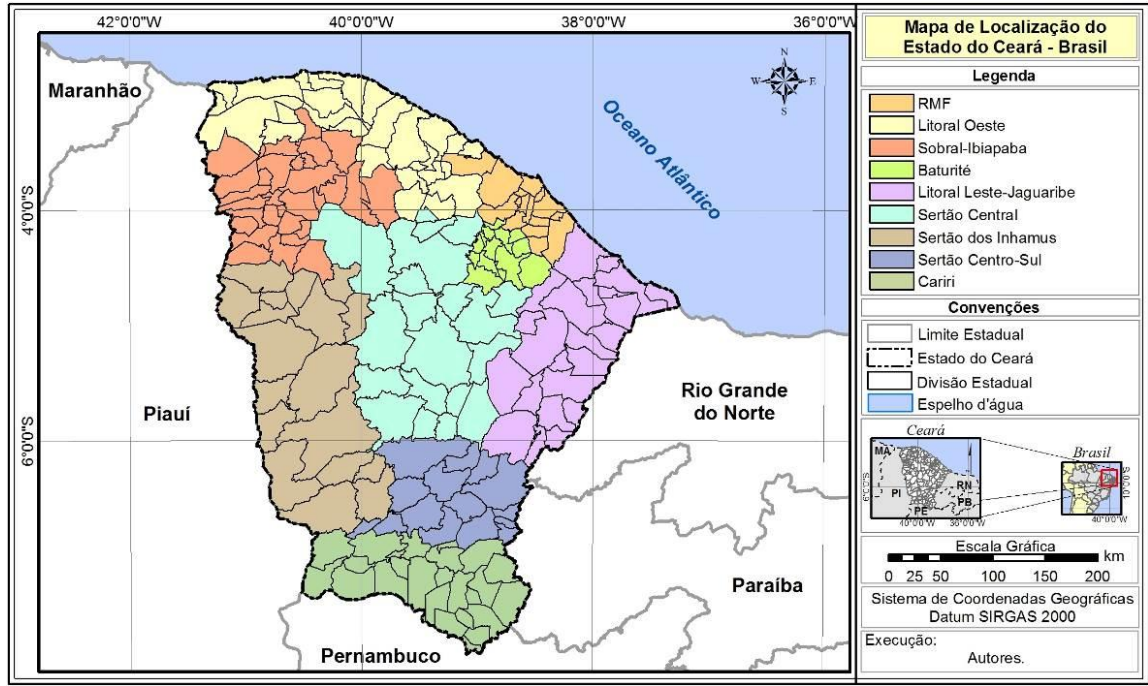

FIGURA 01: Mapa de localização do estado do Ceará, Brasil.

Fonte: João Luís Sampaio Olímpio, Maria Elisa Zanella Autores (2015).

Nestes termos, a presente pesquisa buscou analisar a distribuição espaço-temporal dos desastres naturais, destacando-se os associados à dinâmica climática, ocorridos entre os anos de 2003 a 2013 no estado do Ceará, bem como as consequências negativas dos danos gerados.

\section{MATERIAL E MÉTODO}

Para a elaboração do presente trabalho houve a adoção de um roteiro metodológico norteador das atividades da pesquisa, estando abaixo detalhadas.

Na etapa de gabinete destaca-se a coleta das Portarias de Reconhecimento de Situação de Desastre (PRSD) para Situação de Emergência (SE) e de Estado de Calamidade Pública (ECP), provocadas por eventos naturais adversos, fornecidas pelo Banco de Dados de Registro de Desastres, gerenciado pela Secretaria Nacional de Defesa Civil (SEDEC) para o período de 2003 a 2013, sendo este o recorte temporal de análise.

Assim, as SEs e ECPs decretadas pelos municípios ou pelo Estado que não foram reconhecidas pela União por meio de uma Portaria foram descartadas, uma vez que a circunstância citada indica que não há uma situação de desastre estabelecida.

Contudo, observou-se que em alguns casos as Portarias são publicadas bem depois da ocorrência dos desastres, por vezes no ano seguinte. Assim, para a análise anual deste dado optou-se por empregar o início da vigência do reconhecimento, a qual é emitida logo a após a constituição do desastre.

Também foram utilizados os formulários de Avaliação de Danos (AVADAN), que é o registro nacional oficial de danos decorrentes de desastres. O objetivo deste documento é informar detalhadamente as características dos eventos naturais e dos espaços afetados, além de avaliar os danos e prejuízos, subsidiando a decretação de SE ou ECP.

Os AVADANs foram obtidos a partir do acesso ao Sistema Integrado de Informações sobre Desastres (S2ID), onde se encontram armazenados todos os documentos relacionados a esta 
temática em âmbito nacional. Este banco é gerenciado pelo Departamento de Minimização de Desastres (DMD) pertencente à SEDEC. Entretanto, somente há dados para os anos de 2002 a 2010. Assim, para melhor conformidade com as informações relativas à decretação de SE e ECP, optou-se em excluir o ano de 2002.

$\mathrm{Na}$ etapa laboratorial foi confeccionado o material cartográfico, a partir de informações disponibilizadas pelas instituições relacionadas a esta temática. Em seguida, as informações produzidas e coletadas tiveram seus metadados padronizados, de modo que todas possuíam sistema de coordenadas geográficas e datum horizontal SIRGAS 2000. Foi empregado o software ArcGIS 9.3 (ID: 837871100535), o qual apresenta uma plataforma computacional de um Sistema de informação Geográfica (SIG).

\section{- Desastres, riscos e fenômenos naturais adversos: bases conceituais}

Embora a ocorrência de eventos naturais extremos seja habitual na própria dinâmica do meio natural, sobretudo no que tange aqueles que, direta e indiretamente, estão relacionados à variabilidade climática, estes fenômenos apenas podem ser classificados como desastres quando ocasionam danos aos indivíduos ou em seu espaço.

Neste sentido, eles apenas ocorrem quando um evento adverso atua em um mesmo espaço e tempo, sobre um sistema social vulnerável, que quando impactado não tem meios para superar com seus próprios recursos a crise instalada.

Deve-se ressaltar a diferença conceitual entre risco e desastre. O primeiro é dado enquanto uma situação de probabilidade, de futuro incerto, de que um determinado evento adverso poderá atuar sobre um dado sistema social e que caso se concretize poderá resultar em danos e prejuízos (CASTRO; PEIXOTO; DO RIO, 2005; ISDR, 2004; REBELO, 2008; SOUZA, ZANELLA, 2009).

Já o desastre apenas existe quando há a materialização do risco, dada por uma série de impactos que põem em evidência a magnitude do perigo incidente e de sua relação com a vulnerabilidade presente (KOBIYAMA et al, 2006, MONTEIRO, 2011). Além disso, diante da intensidade das intervenções antropogênicas no ambiente, os desastres naturais tendem a ser mais frequentes e intensos, seja por alterações na dinâmica dos sistemas ambientais, seja pelo uso de áreas suscetíveis a adversidades.

Todavia, diante da necessidade de definir um critério para se estabelecer quando um desastre realmente ocorre, adotou-se a emissão de Portarias de Reconhecimento de Situação de Emergência ou Estado de Calamidade Pública, uma vez que tais documentos são publicados sobre pareceres técnicos que constatam as referidas circunstâncias.

Conforme o artigo $2^{\circ}$ do Decreto $n^{\circ}$ 7.257, de 04.08.2010 (BRASIL, 2010), entende-se por:

- Situação de emergência: situação anormal, provocada por desastres, causando danos e prejuízos que impliquem o comprometimento parcial da capacidade de resposta do poder público do ente atingido, e;

- Estado de calamidade pública: situação anormal, provocada por desastres, causando danos e prejuízos que impliquem o comprometimento substancial da capacidade de resposta do poder público do ente atingido (BRASIL, 2010).

Também se faz necessário definir conceitualmente os fenômenos adversos. De acordo com Oliveira (2006), as secas foram definidas pela Convenção das Nações Unidas de Combate à 
Desertificação como um fenômeno que ocorre naturalmente quando a precipitação registrada é significativamente inferior aos valores normais, provocando desiquilíbrio hídrico e afetando os sistemas de produção dos recursos naturais.

De acordo com o Glossário de Defesa Civil e Estudos de Riscos de Medicina dos Desastres (CASTRO, CALHEIROS, MOURA, 2004) o conceito de seca apresenta quatro definições, que são apresentadas abaixo:

- Ausência prolongada, deficiência acentuada ou fraca distribuição de precipitação;

- Período de tempo seco, suficientemente prolongado, para que a falta de precipitação provoque grave desequilíbrio hidrológico;

- Do ponto de vista meteorológico, a seca é uma estiagem prolongada, caracterizada por provocar uma redução sustentada das reservas hídricas existentes; e,

- Numa visão socioeconômica, a seca depende muito mais das vulnerabilidades dos grupos sociais afetados que das condições climáticas (CASTRO, CALHEIROS, MOURA, 2004, não paginado).

Nesta pesquisa, considerou-se que as secas são eventos naturais, que ocorrem periodicamente na região Nordestina. No entanto, não é possível dissociar o fenômeno natural das suas consequências sobre a população sertaneja, onde o quadro social, econômico, político e cultural estruturou-se sobre a escassez hídrica.

Já as estiagens correspondem ao período do ano que habitualmente é mais seco, com ausência ou redução das precipitações.

Com relação à definição de inundações, considera-se como o processo de extravasamento do canal de uma drenagem, atingindo as áreas marginais (PINHEIRO, 2007). Segundo Castro, Calheiros e Moura (2004) elas podem ser classificadas em inundações graduais, inundações bruscas (enxurradas), inundações litorâneas e alagamentos. Vale ressaltar que na área de estudo apenas os dois primeiros fenômenos são indutores de danos que ocasionam desastres naturais.

\section{- Dinâmica e variabilidade climáticas regionais}

A dinâmica climática da região Nordeste do Brasil (NEB) é controlada por diferentes massas de ar e centros de ação, destacando-se a atuação do Anticiclone Semifixo do Atlântico Sul, associados a Massa Tropical Atlântica e a Massa Equatorial Atlântica. Em função de sua vorticidade produzem ventos dominantemente do quadrante E-SE, consistindo nos Alísios de sudeste.

Por outro lado, a subsidência do ar ocasiona a estabilidade no tempo, instituindo o período seco que pode persistir até nove meses. Esta situação é interrompida por diversos sistemas sinóticos que atuam em períodos e regiões conhecidos, embora passível de modificação, em razão de fatores inibidores ou intensificadores da nebulosidade (ZANELLA, 2014).

O principal sistema produtor de chuvas no estado do Ceará é Zona de Convergência Intertropical (ZCIT), que atua entre os meses de fevereiro a maio, estabelecendo a quadra chuvosa. Este realiza um deslocamento sazonal entre os hemisférios norte e sul, de modo que em anos normais, ele migra de sua posição mais setentrional (em torno de $14^{\circ} \mathrm{N}$ ), durante agosto-setembro, para sua posição mais ao sul (em torno de $2^{\circ} \mathrm{S}$ ), entre março-abril. 
Contudo, apresenta alta variabilidade interanual no posicionamento, intensidade e persistência, sendo modulada pelos padrões termodinâmicos sobre as bacias oceânicas do Atlântico e Pacífico equatoriais, ocasionando os fenômenos de dipolo do Atlântico e El Niño Oscilação Sul (ENOS), respectivamente (FERREIRA; MELLO, 2005; MELO et al, 2009).

O dipolo do Atlântico é formado por uma anomalia da Temperatura da Superfície do Mar (TSM) com características opostas entre as bacias norte e sul do Atlântico tropical, tendo como resultado a intensificação ou minimização das precipitações em um dos hemisféricos, enquanto no outro gera efeitos opostos.

Assim, as chuvas abaixo da média no NEB, durante a quadra chuvosa, estão correlacionadas à fase positiva do dipolo, quanto a TSM do Atlântico tropical sul está mais baixa que a do norte, ocasionando o deslocamento da ZCIT para latitudes acima da linha do Equador. Já em anos chuvosos, observa-se que as TSM do Atlântico sul estão mais quentes que do Atlântico norte, produzindo a intensificação dos Alísios de nordeste e o deslocamento da ZCIT para o sul (FERREIRA; MELLO, 2005; MELO et al, 2009; UVO, 1989).

Por sua vez o ENOS é um fenômeno de macroescala formado pela anomalia da TSM do Pacífico equatorial, próxima da costa peruana. Sob condições normais, nesta região ocorrem ressurgências de águas frias, entretanto a variabilidade térmica local permite que o ENOS apresente duas fases: uma quente (El Niño) e outra fria (La Niña).

Sobre o NEB, o El Niño tende a favorecer os anos secos, pois pode provocar alterações na circulação da célula Walker, induzindo a uma subsidência do ar nesta região, o que inibe a migração da ZCIT para posições mais meridionais. Por outro lado, a La Niña tende a ocasionar anos chuvosos, pois intensifica a nebulosidade sobre o NEB. Na Tabela 01 é exposta a situação dos fenômenos acima descritos na série histórica estudada.

Além da ZCIT, outros sistemas também contribuem para a precipitação da estação chuvosa, a saber: o Vórtice Ciclônico de Ar Superior (VCAS), que atuam na pré-estação, especialmente em janeiro e fevereiro; as Linhas de Instabilidade que ocorrem em fevereiro e março; os Complexos Convectivos de Mesoescala que são formados por condições locais favoráveis; os Distúrbios Ondulatórios de Leste, produzindo chuvas de pós-estação.

Por fim, o sul do estado é afetado por incursões das Repercussões das Frentes Frias, ocasionando precipitações, principalmente nos meses iniciais do ano.

TABELA 01: Situação de ENOS, Dipolo do Atlântico e a situação pluviométrica resultante entre 2003 a 2013.

\begin{tabular}{cccc}
\hline Anos & El Niño/La Nina & Dipolo do Atlântico & Situação Pluviométrica \\
\hline 2003 & El Niño fraco & Negativo & Habitual \\
2004 & Neutro & Neutro & Chuvoso a Muito chuvoso \\
2005 & El Niño fraco & Positivo & Seco \\
2006 & La Niña fraca & Neutro & Habitual \\
2007 & Neutro & Positivo & Habitual a Seco \\
2008 & La Niña moderada & Negativo & Chuvoso \\
2009 & La Niña fraca & Negativo & Muito Chuvoso \\
2010 & El Niño forte & Neutro & Seco a Muito Seco \\
2011 & La Niña Moderada & Negativo & Habitual a chuvoso \\
2012 & La Niña fraca & Positivo & Seco \\
2013 & Neutro & Positivo & Seco a Muito Seco \\
\hline
\end{tabular}


Fonte: adaptado de CPC (2015), Monteiro (2011).

\section{RESULTADOS E DISCUSSÃO}

De acordo com os dados da SEDEC, no estado do Ceará, entre 2003 a 2013, foram emitidas 1.824 Portarias de Reconhecimento de SE ou ECP, sendo que 1.820 foram decorrentes de eventos naturais associados à dinâmica climática. Também houve quatro decretações de SE relacionadas à intensificação dos processos erosivos. Deste modo, os desvios positivos e negativos da pluviosidade são os principais responsáveis pelos registros de PRSD neste território, fruto da variabilidade climática da região semiárida nordestina (Tabela 02).

TABELA 02: Distribuição das Portarias de Reconhecimento de SEs e ECPs.

\begin{tabular}{ccccc}
\hline Anos & Estiagem/Seca & Enchente & Enxurrada & Erosão \\
\hline 2003 & 90 & 22 & 0 & 0 \\
2004 & 27 & 67 & 0 & 0 \\
2005 & 298 & 0 & 0 & 0 \\
2006 & 192 & 0 & 0 & 0 \\
2007 & 277 & 0 & 0 & 1 \\
2008 & 62 & 39 & 0 & 0 \\
2009 & 1 & 107 & 14 & 1 \\
2010 & 83 & 0 & 0 & 1 \\
2011 & 6 & 2 & 3 & 1 \\
2012 & 176 & 0 & 1 & 0 \\
2013 & 352 & 0 & 1 & 0 \\
Total & 1.564 & 237 & 19 & 4 \\
\hline
\end{tabular}

Fonte: SEDEC, 2003-2013.

As estiagens e as secas são os eventos naturais mais frequentes e significativos na série histórica analisada, distribuindo-se por todo o estado, mas principalmente nos municípios do sertão semiárido, caracterizado por um espaço natural extremamente frágil e bastante degradado, além de habitado por uma parcela significativa da população mais vulnerável às manifestações destes eventos. Por outro lado, a região em estudo também é suscetível aos eventos pluviais concentrados ou por um período chuvoso muito intenso, expondo as pessoas usuárias das planícies de inundações.

\section{- Distribuição das Estiagens/Secas}

Na série histórica analisada, as estiagens/secas foram responsáveis pela decretação de 1.563 SEs e 1 (um) ECP, correspondendo a 85,7\% dos registros e afetando 180 (97,8\%) municípios. Ressalta-se que este fenômeno apresenta uma ampla distribuição espacial, estando presente em todas as regiões, mas atingindo, sobretudo, o sertão devido às características naturais, socioeconômicas e culturais reinantes.

$\mathrm{Na}$ análise da distribuição dos registros de desastres decorrentes de estiagens e secas é observado que houve decretações de desastres em todos os anos da série, porém com frequências diferenciadas entre os mesmos, que variam conforme a intensidade da seca (Figura 02). 
O ano de 2003 foi enquadrado como habitual, resultando em 89 SEs e um ECP promovidos pelas secas. Os impactos foram dispersos por todo o território, mas afetaram principalmente os municípios dos Sertões Central, dos Inhamus e Médio Jaguaribe.

Em 2004, as condições atmosféricas foram favoráveis às chuvas. Contudo, também ocorreram impactos promovidos pelas estiagens, resultando na decretação de 27 SEs, concentradas nos municípios dos Sertões Central e dos Inhamus e do Cariri.

Entre os anos de 2005 a 2007 ocorreu uma sequência de anos seco, habitual e muito seco, respectivamente, caracterizando uma situação de seca, sendo responsável pelo pico de decretações de desastres naturais da série histórica. Nestes anos foram reconhecidos 768 decretos de SE, sendo que apenas um não foi produzido pela escassez hídrica (erosão marinha no município de Caucaia, em 2007), correspondendo a $42,1 \%$ do total de desastres registrados em toda a série histórica.

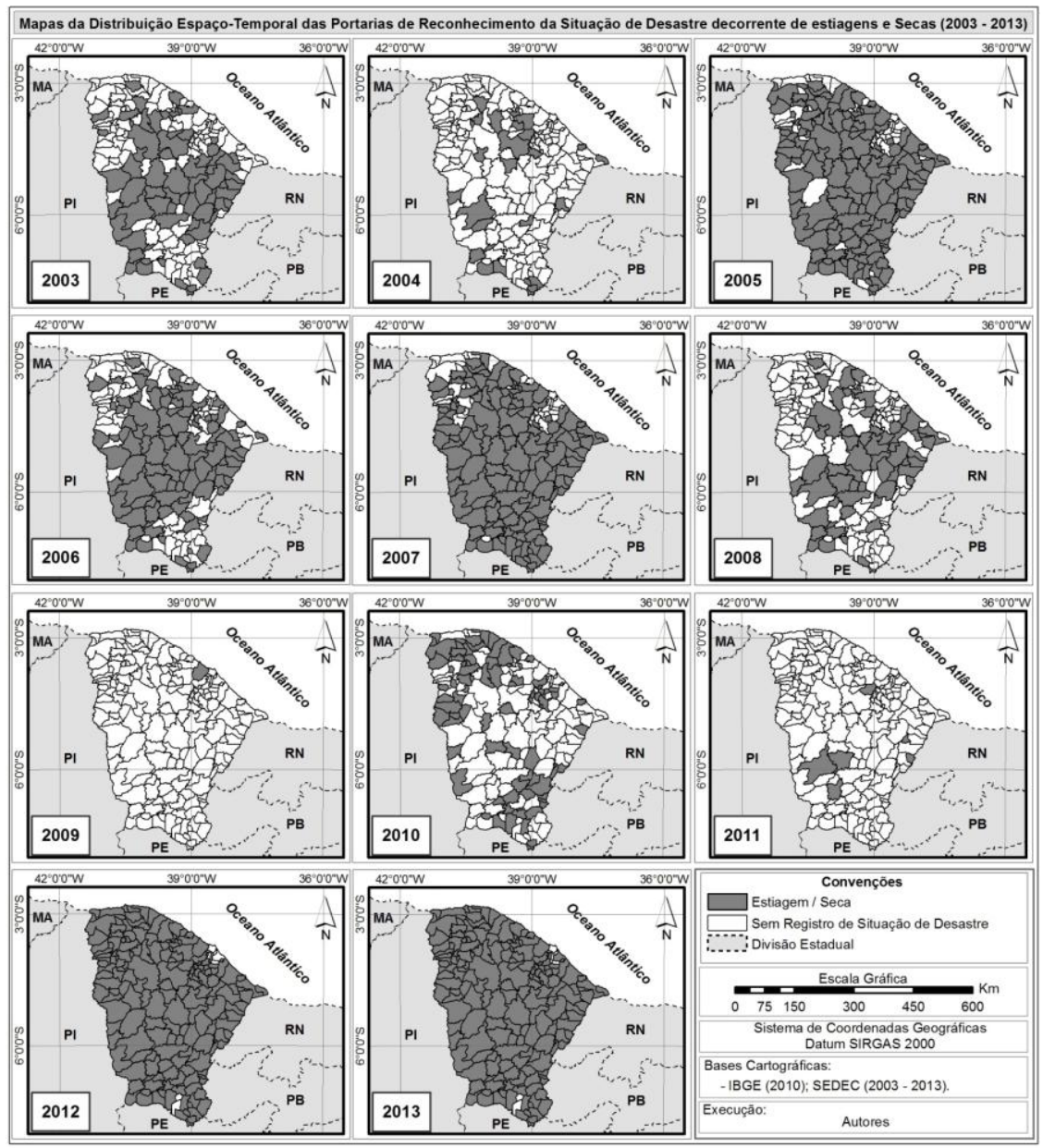

FIGURA 02: Mapas da distribuição espaço-temporal das Portarias de Reconhecimento da Situação de Desastre decorrentes de estiagens e secas (2003 - 2013).

Fonte: Olímpio (2013).

O ano de 2005 foi um dos mais representativos da série histórica, tendo sido decretadas 298 SEs, distribuídas por todo o território cearense e afetando a maioria dos municípios dos 
Sertões Central e dos Inhamus, Litoral Leste e Oeste, região do Cariri, médio Jaguaribe e Ibiapaba.

Entretanto, houve uma concentração de municípios que não decretaram SE em parte da Região Metropolitana de Fortaleza (RMF) e na Serra de Baturité. No primeiro caso devido ao sistema de abastecimento mais eficiente, transferindo as águas de um conjunto de reservatórios pertencentes às bacias jaguaribana e metropolitana. Já a segunda região, provavelmente, está relacionada ao ambiente serrano que devido ao fator orográfico apresenta maior disponibilidade hídrica.

No ano de 2006 houve 192 registros de SE, concentrando-se, novamente, nos Sertões Central e dos Inhamus e médio Jaguaribe. Já em 2007 foram decretadas 278 SEs, distribuídas em todas as regiões, mas afetando com maior proeminência as mesmas regiões do ano anterior, além do Cariri. A RMF e a Serra de Baturité concentraram, novamente, os municípios que não registraram situação de desastres.

$\mathrm{O}$ ano de 2008 enquadrou-se como chuvoso. Deste modo, das 134 SEs reconhecidas, apenas 62 decorreram do fenômeno da estiagem. Ressalta-se que parte destes impactos são reflexos da seca dos anos anteriores. Novamente, as regiões mais afetadas foram os Sertões Central e dos Inhamus e o médio Jaguaribe.

Já o ano de 2009 foi classificado como muito chuvoso, sendo registrado apenas uma SE decorrente da escassez hídrica no município de Caucaia. A quadra chuvosa de 2010 esteve entre seca a muito seca, resultando em 83 SEs. Já em 2011 ocorreram 13 SEs, sendo que 6 estiveram relacionados às estiagens. Em ambos não houve uma concentração espacial bem definida.

Nos anos de 2012 a 2013 houve uma seca de grande intensidade sobre o estado. No primeiro, 176 (95,7\%) municípios tiveram reconhecidas SEs, muito dos quais a partir de um único decreto emitido pelo governo estadual. Em 2013, foram reconhecidas 352 Portarias, que afetaram 176 municípios. Apenas não houve situação de desastre oficialmente decretada em alguns municípios da RMF, da Região Metropolitana do Cariri e no município serrano de Guaramiranga.

\section{- Distribuição das Inundações}

As inundações promoveram 256 registros, sendo que 11 resultaram em EPCs e 245 em SEs, estando distribuídas entre 146 (79,6\%) municípios. Deste total, as enchentes foram responsáveis por 237 desastres, impactando 135 municípios. Já as enxurradas afetam esporadicamente o Ceará, estando condicionadas aos eventos pluviais extremos e limitandose aos municípios serranos e os situados nos sopés dos planaltos (Figura 03).

Dos 122 registros para o ano de 2003, houveram 22 Portarias de SE motivadas por inundações, afetando 14 municípios, com destaque para as regiões Sobral-Ibiapaba, Litoral Oeste e da RMF.

Em 2004, ano considerado chuvoso a muito chuvoso, os registros de desastres de inundações distribuíram-se por todo o Ceará, mas com maior destaque nas regiões do Sertão dos Inhamus, Sertão Central, do Cariri e Litoral leste-jaguaribe. 
Como exposto os anos de 2005, 2006 e 2007 foram anos marcados por um prolongado período de secas, não havendo registrados de desastres promovidos pelos desvios positivos da pluviosidade.

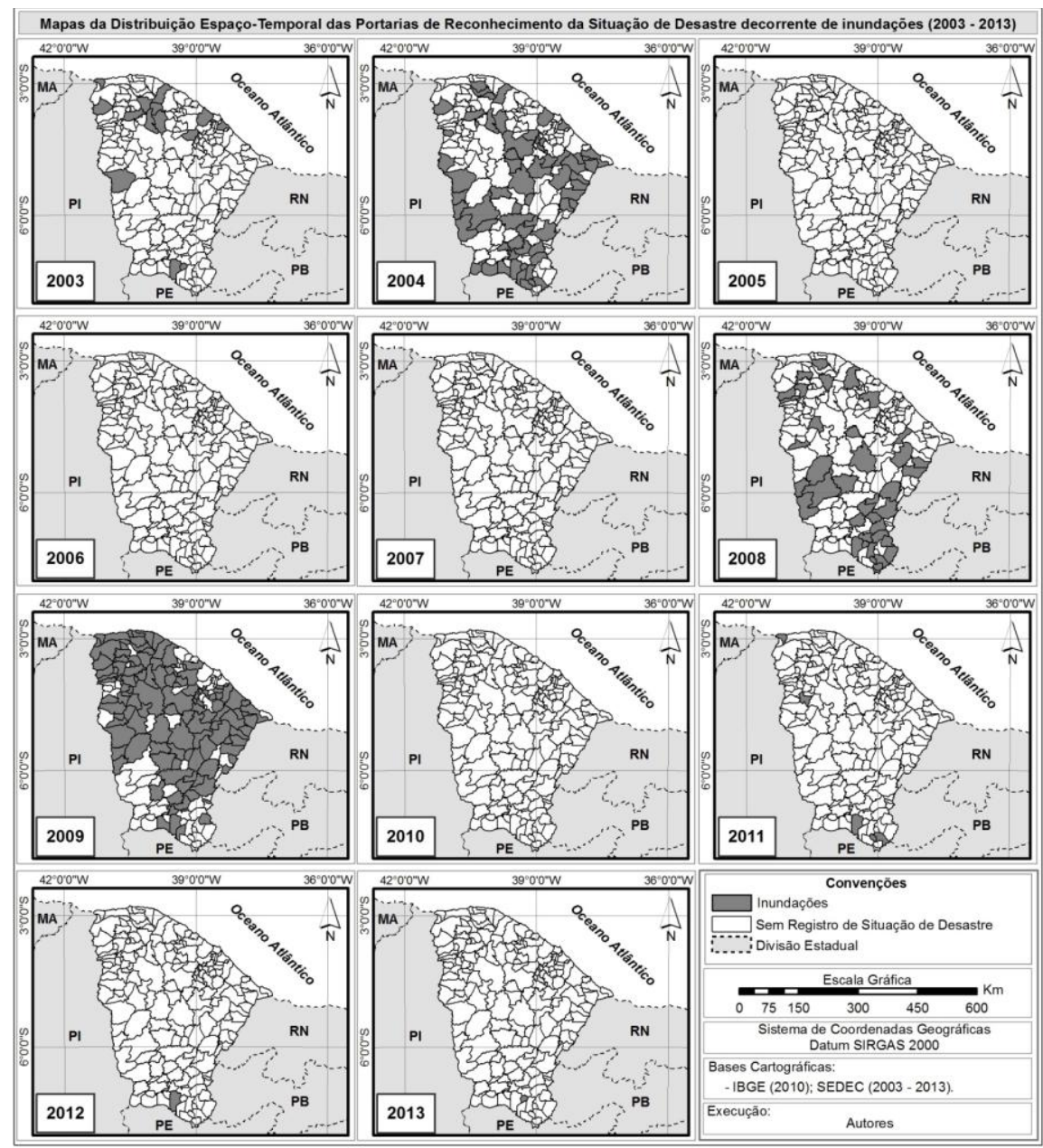

FIGURA 03: Mapas da distribuição espaço-temporal das Portarias de Reconhecimento da Situação de Desastre decorrentes de inundações (2003 - 2013).

Fonte: Olímpio (2013).

O ano de 2008 foi chuvoso, sendo reconhecidas 39 decretações de SE motivadas pelos danos decorrentes das inundações. As regiões mais afetadas foram do Cariri, Sertão Centro-sul e Sertão dos Inhamus.

Em termos quantitativos, o ano de 2009 foi o mais significativo e de maior abrangência espacial. Foram reconhecidas $121 \mathrm{SEs}$, sendo que 107 foram motivadas pelas enchentes e 14 por enxurradas. As inundações atingiram diversos municípios em todas as bacias do estado, mas com maior ênfase nas regiões dos Sertões Central, dos Inhamus, Litoral Leste-jaguaribe, Sobral-Ibiapaba e Litoral oeste. Já as enxurradas concentraram-se nas regiões de Baturité e Sobral-Ibiapaba.

No ano de 2010 também não foram registrados desastres decorrentes de inundações, uma vez que este apresentou precipitações abaixo das médias. Em 2011, foram reconhecidas 5 Portarias de SE, sendo que duas foram produzidas por enchentes. As demais foram motivadas por enxurradas nos municípios de Crato, Porteiras e Ipú. 
Nos anos de 2012 e 2013 ocorreu uma seca, de modo que apenas foram reconhecidos dois ECP, um para cada ano, afetando municípios de Crato e Juazeiro do Norte, região do Cariri, respectivamente.

\section{- Desastres naturais: uma situação recorrente}

A partir das informações obtidas verificou-se que alguns municípios apresentam recorrência na decretação de desastres associados ao clima. Esta situação indica que os eventos naturais intensos ocorrem com alta frequência, mas também adverte que a população e as instituições públicas possuem baixa resiliência, uma vez que após serem atingidas por um evento adverso, elas não têm meios para prever, prevenir e mitigar futuros desastres, a partir da experiência vivida. Assim, constantemente sofrem com os mesmos danos, tornando a situação de risco uma constante na vida das pessoas.

Dos 184 municípios cearenses, 180 tiveram reconhecidas pelo menos uma vez uma decretação de SE ou ECP motivada por escassez hídrica, além disso, 16,8\% dos municípios se concentraram na classe de frequência "Muito Baixa" e 28,3\% na "Baixa" indicando que alguns municípios são frequentemente impactados pela escassez hídrica, entretanto apresentam melhores condições para resistir os eventos de menor intensidade (Tabela 03). Todavia, houve uma maior frequência na classe "Moderada", com os municípios que tiveram reconhecidas de 08 a 11 decretações (Figura 04).

Os municípios com maiores frequências foram Tauá e Penaforte, os quais em oito dos onze anos da série histórica tiveram reconhecidos 18 decretos de SE ou ECP, muito dos quais indicando estado de agravamento dos impactos sentidos. As regiões mais afetadas foram os sertões dos Inhamus e Central.

Esta situação, como de outros municípios, decorre de um contexto de elevada vulnerabilidade socioambiental, marcada por um espaço natural suscetível a ocorrência das secas, além de um alto estado de degradação. Além disso, parte majoritária da população interiorana não possui meios técnicos, financeiros e conhecimento para superar as adversidades proporcionadas pela escassez hídrica.

TABELA 03: Classes de frequência de PRSD decorrentes de secas/estiagens

\begin{tabular}{ccccc}
\hline Tipologia & Intervalo & $\mathrm{f}$ & $\mathrm{fr}$ & $\mathrm{fi}$ \\
\hline Ausente & 0 & 4 & 2,2 & 4 \\
Muito Baixa & $01 \vdash 04$ & 31 & 16,8 & 35 \\
Baixa & $04 \vdash 08$ & 52 & 28,3 & 87 \\
Moderada & $08+12$ & 72 & 39,1 & 159 \\
Alta & $12 \vdash 16$ & 22 & 12,0 & 181 \\
Muito alta & 16 H 18 & 3 & 1,6 & 184 \\
\hline Legenda: $f$ - frequência; fr - frequência \\
relativa; fi - frequência acumulada absoluta \\
\hline \multicolumn{5}{c}{ Fonte: SEDEC, 2003-2013. }
\end{tabular}

Acrescenta-se um quadro de poucas ações efetivas de prevenção de desastres realizadas pelas entidades públicas. Por fim, outro fator agravante é a própria cultura do sertanejo, habituado a conviver com um sentimento de esperança, na verdade, de passividade diante da seca, aguardando a ajuda do Poder Público e principalmente das "benesses de Deus". 


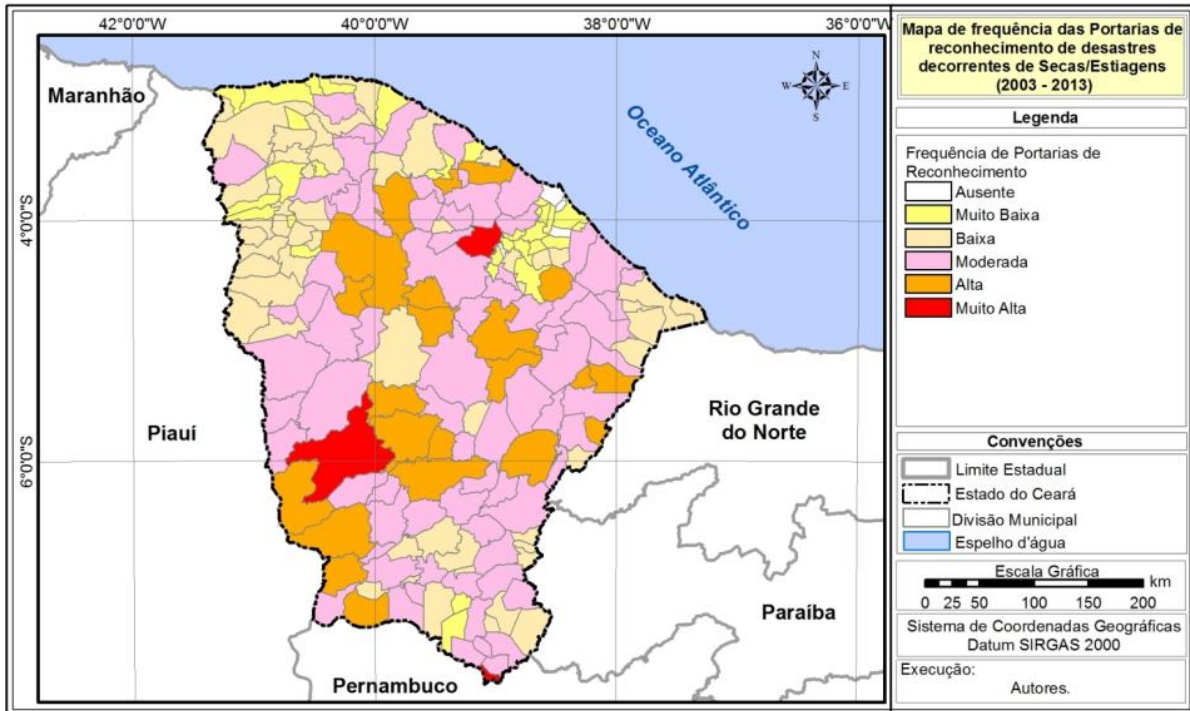

FIGURA 04: Mapas de frequência das Portarias de Reconhecimento da Situação de Desastre decorrentes de secas/estiagens (2003 - 2013).

Fonte: Olímpio (2013).

Os dados também revelam que alguns municípios apresentam baixa vulnerabilidade ao fenômeno das secas. Estes se concentram na RMF, no litoral oeste e na Ibiapaba, devido a maior disponibilidade hídrica destas regiões.

No primeiro caso, a transposição das águas da bacia do rio Jaguaribe para o complexo hídrico dos açudes Pacoti-Gavião-Riachão é uma das ações para o abastecimento das principais cidades do estado, bem como garantindo a oferta de água para as atividades produtivas, destacando os polos industriais metropolitanos. As outras regiões possuem clima sub-úmido e úmido, havendo uma maior disponibilidade de água nos reservatórios naturais e artificiais.

Do mesmo modo que estiagens, as inundações são desastres recorrentes em alguns municípios (Tabela 04). Os dados referentes às PRSD das inundações apontam que a maioria dos municípios registrou apenas uma $(41,3 \%)$ ou duas $(22,3 \%)$ situações de desastres. Em seguida, $12,0 \%$ registraram três situações de desastres e 3,3\% entre quatro a cinco decretações. A classe muito alta abrangeu apenas um município (Crato). Por fim, 38 municípios $(20,7 \%)$ nunca decretaram ou não tiveram reconhecidas situações de desastres produzidos por inundações na série em foco (Figura 05).

Com relação à frequência das Portarias de reconhecimento, observa-se que os municípios das bacias dos rios Salgado, Aracatiaçu, Acaraú (regiões de Sobral-Ibiapaba e Litoral Oeste) e Jaguaribe foram os mais atingidos pelas inundações. O município do Crato foi o que apresentou a maior frequência, motivados pelas inundações do canal do rio Granjeiro, contribuinte do rio Salgado. 
TABELA 04: Classes de frequência de PRSD decorrentes de inundações

\begin{tabular}{ccccc}
\hline Classe & Intervalo & $\mathbf{f}$ & $\mathbf{f r}$ & $\mathbf{f i}$ \\
\hline Ausente & 0 & 38 & 20,7 & 38 \\
Muito Baixa & $01 \vdash 02$ & 76 & 41,3 & 114 \\
Baixa & $02 \vdash 03$ & 41 & 22,3 & 155 \\
Moderada & $03 \vdash 04$ & 22 & 12,0 & 177 \\
Alta & $04 \vdash 06$ & 6 & 3,3 & 183 \\
Muito alta & 06 H 07 & 1 & 0,5 & 184 \\
\hline & Fonte: SEDEC, 2003-2013. & &
\end{tabular}

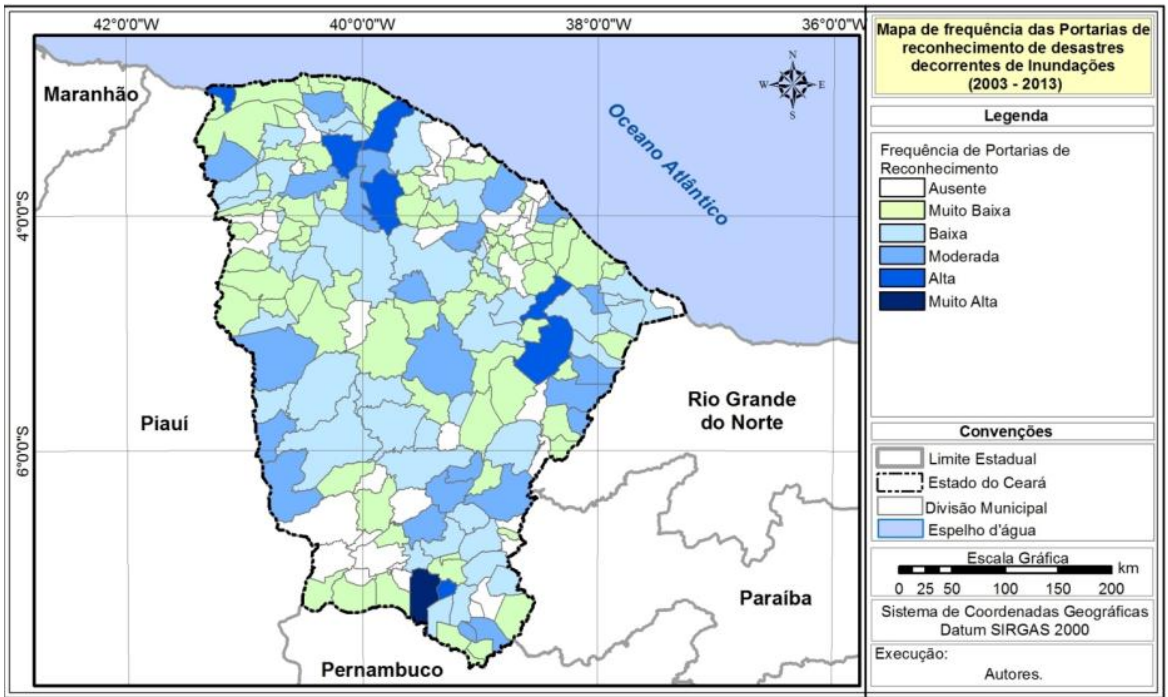

FIGURA 05: Mapas de frequência das Portarias de Reconhecimento da Situação de Desastre decorrentes de inundações $(2003-2013)$.

Fonte: Olímpio (2013).

\section{- Os impactos sobre a sociedade cearense}

Embora os desvios positivos e negativos da pluviosidade sejam característicos da região semiárida nordestina, a sociedade brasileira ainda não aprendeu e nem apresentou interesse político necessário para buscar soluções eficientes, que possam gerir os riscos, por meio de ações que visem o uso dos recursos naturais mais adequado às condições naturais impostas, bem como a melhoria das condições socioeconômicas.

No caso cearense, desde o início do seu processo de formação até os dias atuais, os eventos adversos decorrentes da variabilidade climática, principalmente as secas, são os que mais ocasionaram impactos na população, na economia e na organização do espaço, refletindo em diversos problemas sociais, econômicos e ambientais que afligem os sertanejos e citadinos.

Infelizmente, na maioria dos casos, as obras de minimização dos impactos destes eventos estão relacionadas a interesses específicos, como o abastecimento da capital, dos polos industriais e do agronegócio, que embora tenham uma importância para a economia e na geração de renda, não atendem a maior parte da população interiorana, principalmente dos grupos mais vulneráveis. 


\section{- Danos ocasionados pela escassez hídrica}

No período histórico analisado, as secas/estiagens apresentam amplo predomínio entre os eventos naturais que promoveram impactos. Entre os anos de 2003 a 2010, foram registrados 759 AVADANs informando danos originados da variabilidade climática, sendo que deste montante $73,7 \%$ foram provocados pelas secas (Gráfico 01). Ressalta-se que além destes AVADANs, também foram registrados mais 176, pois alguns municípios emitiram mais de um formulário no mesmo ano para a mesma tipologia de evento, devido à intensificação dos danos ou para a complementação de informações. Assim, estes últimos foram considerados como informações a parte, optando-se por apenas selecionar os dados que indicam um agravamento da situação relatada no primeiro AVADAN.

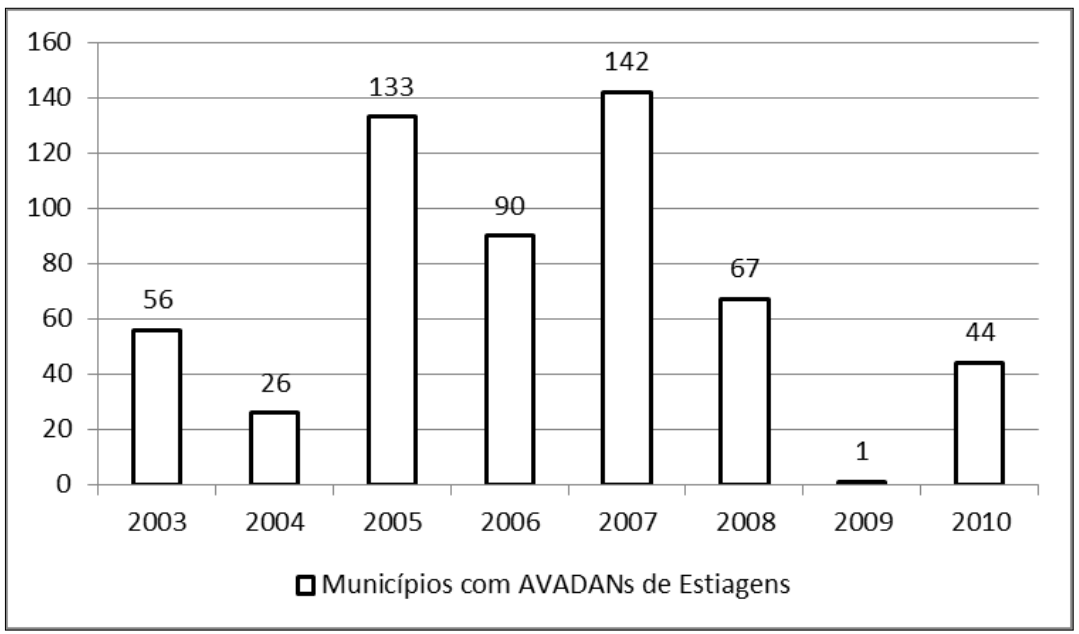

GRÁFICO 01: Distribuição interanual dos AVADANs de estiagens/secas no estado do Ceará Fonte: SEDEC (2003 / 2010).

Conforme exposto, os anos que mais apresentaram registros de danos e prejuízos decorrentes de estiagens e secas foi o triênio 2005, 2006 e 2007, enquanto o ano de 2009 apresentou menos.

Nos anos de 2004 e 2008, embora tenham ocorrido chuvas acima da média, foram registrados 26 e 67 AVADANs, respectivamente, em virtude dos próprios efeitos do período de estiagem sazonal. Situação diferente do ano de 2003, considerado habitual, mas com danos apenas inferiores ao triênio 2005-2007.

Quanto à distribuição mensal, é durante os meses de maio e junho que ocorrem o maior número de registros de danos decorrentes das secas (Gráfico 02). Neste sentido, os danos foram produzidos durante a estação chuvosa, mas quando esta possuiu precipitações inferiores aos valores normais. Esta mesma situação pode ser identificada nos registros de março e abril. 


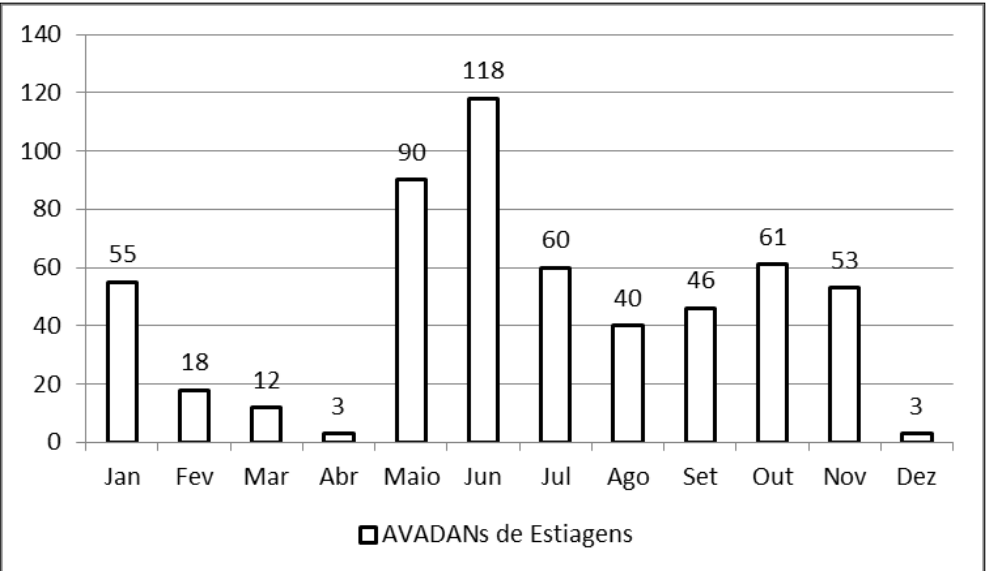

GRÁFICO 02: Distribuição mensal dos AVADANs de secas/estiagens no estado do Ceará Fonte: SEDEC (2003 / 2010).

A ausência de precipitações no período chuvoso ocasiona danos mais significativos do que os ocorridos durante o período de estio, pois é durante o primeiro que o sertanejo planta e intensifica a pecuária, garantindo recursos para o restante do ano. No segundo semestre, o homem do campo desenvolve outras atividades (construção civil, comércio, extração vegetal e mineral, etc.) que podem ser realizadas sem a dependência das precipitações. Além disso, estas chuvas são fundamentais para o abastecimento dos núcleos rurais, de modo que durante as secas a população sofre com os baixos níveis de água dos mananciais, bem como com sua a reduzida qualidade.

As estiagens afetaram, sobretudo, as áreas rurais, destacando-se, mais uma vez, os anos de 2005 a 2007 (Gráfico 03). Ressalta-se que os danos sobre o espaço urbano são bastante inferiores aos rurais e decorrem, principalmente, do desabastecimento das sedes municipais.

Os danos foram mais frequentes nas áreas residenciais rurais e nas áreas agrícolas, voltadas para os cultivos de subsistência (Tabela 05). Nas cidades, estiveram relacionados ao desabastecimento das zonas urbanas residenciais.

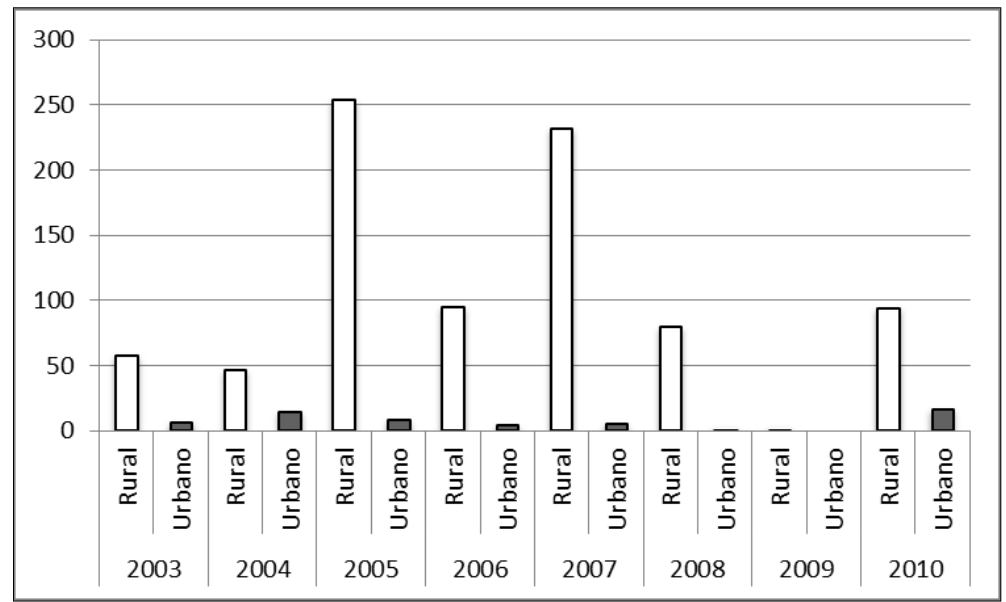

GRÁFICO 03: Danos decorrentes das secas/estiagens entre as zonas rurais e urbanas Fonte: SEDEC (2003 / 2010). 
TABELA 05: Tipologia dos usos rurais e urbanos afetados pelas estiagens e secas

\begin{tabular}{lrr}
\hline Tipo de Uso & Rural & \multicolumn{2}{c}{ Urbano } \\
\hline Residencial & 464 & 36 \\
Comercial & 04 & 03 \\
Industrial & 03 & 01 \\
Agrícola & 344 & 09 \\
Pecuária & 38 & 02 \\
Extrativismo & 02 & 00 \\
Turismo e outras & 06 & 04 \\
\hline
\end{tabular}

Fonte: SEDEC (2003 / 2010).

No que tange às tipologias dos danos humanos, as estiagens e as secas caracterizam-se por atingir uma grande porção espacial e, consequentemente, afetam muitos indivíduos, todavia seus impactos ocorrem de forma gradual. À medida que as chuvas não ocorrem a situação vai agravando-se até atingir uma linha de ruptura, a partir da qual se inicia a situação de crise. Alguns danos humanos como mortes e enfermidades, embora sejam consequências indiretas das estiagens, são atribuídas a outros fatores, tais como as doenças e a pobreza, mas na verdade são elementos indicadores da vulnerabilidade destes grupos frente a estes fenômenos.

Os registros de danos e prejuízos indicam que $99,7 \%$ dos danos humanos provocados pela escassez hídrica encontram-se inseridos na classe afetada, por esta ser mais abrangente, abarcando qualquer indivíduo que foi atingido de alguma forma pelo evento natural ou que se enquadrou em mais de uma das outras tipologias.

A maior quantidade dos registros de pessoas afetadas ocorreu durante os anos de 2005 a $2007 \mathrm{com} 75,6 \%$ do total desta classe na série histórica enfocada. Entre os municípios notase que alguns se apresentam mais vulneráveis, a partir da análise da variável "pessoas afetadas". Estes se encontram, em maior parte, nas regiões dos Sertões Central e dos Inhamus, porções do território cearense cujas condições naturais, sociais e econômicas são favoráveis aos desastres das secas.

Dos 559 AVADANs decorrentes das estiagens e secas, 367 relataram que os municípios sofreram prejuízos econômicos, destacando-se as atividades agrícola $(94,6 \%)$ e pecuária $(5,5 \%)$.

No que tange aos prejuízos sociais, houve o predomínio dos impactos decorrentes da falta de abastecimento dos núcleos populacionais, sobretudo os situados na zona rural. Foram registrados 468 AVADANs informando esta situação, destacando-se, mais uma vez, no triênio de 2005 a 2007 com 65,2\% do total de registros.

Em seguida, a análise do vulto dos prejuízos econômicos indicou que os danos foram predominantemente das classes "Média" (32,7\%) e "Pouco Importante" (29,0\%), estando relacionados, principalmente, a falta de abastecimento de água (Gráfico 04). 


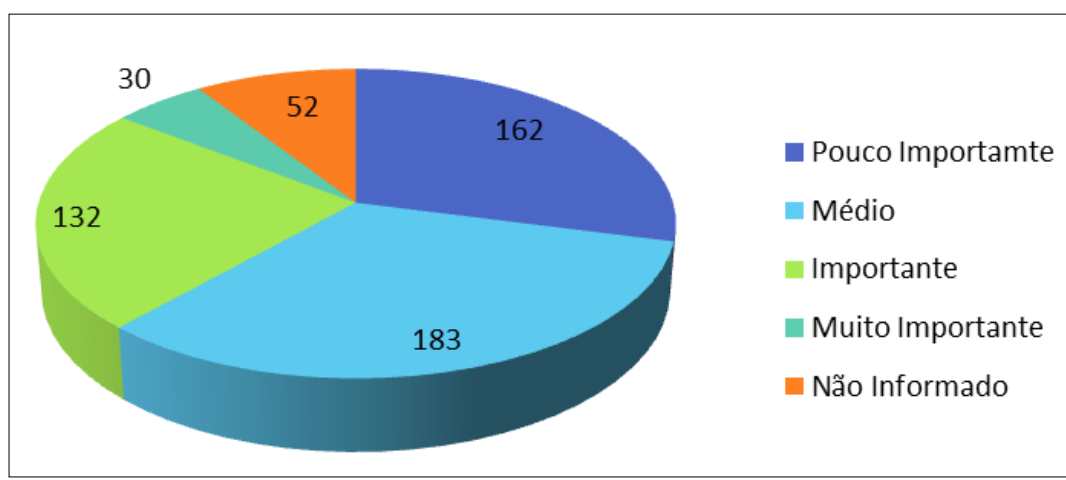

GRÁFICO 04: Intensidade dos prejuízos econômicos decorrentes de secas/estiagens Fonte: SEDEC (2003 / 2010).

\section{- Danos ocasionados pelo excesso hídrico}

Entre 2003 a 2010 foram registrados 200 formulários AVADANs, sendo 187 decorreram de enchentes e 13 de enxurradas. Os danos foram mais frequentes nos anos de 2009, 2008 e 2004. Em 2006, 2007 e 2010 não foram registrados (Gráfico 05).

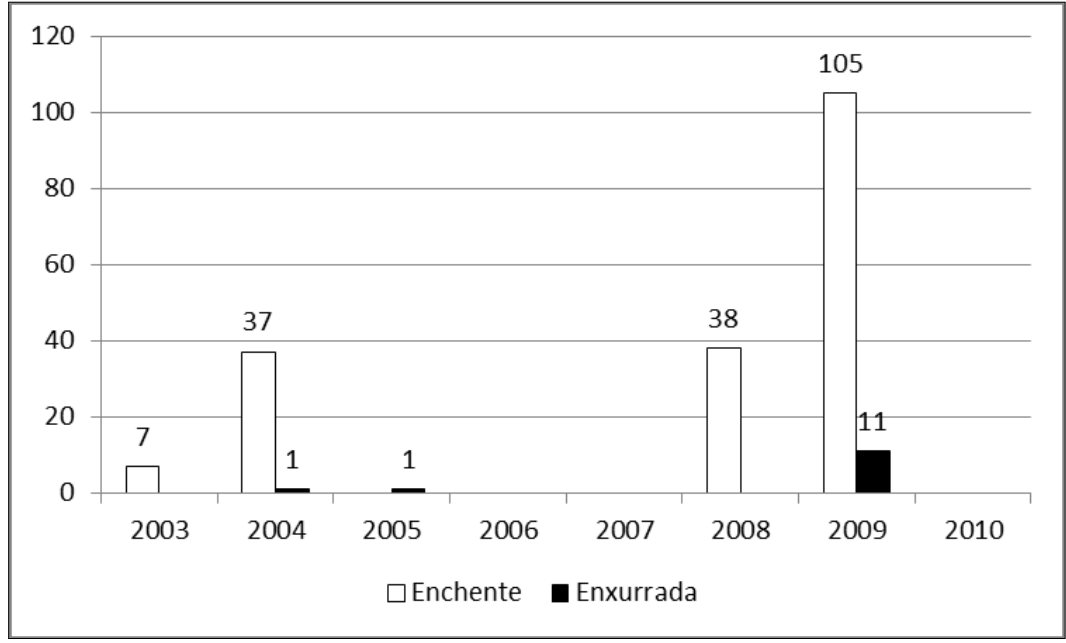

GRÁFICO 05: Distribuição interanual dos registros de AVADANs de inundações no estado do Ceará Fonte: SEDEC (2003 / 2010).

No que tange a distribuição mensal, observa-se que $91,54 \%$ dos AVADANs estão concentrados nos meses da quadra chuvosa, destacando-se maio $(49,8 \%)$. Esta situação agrava-se tendo em vista que as bacias fluviais e lacustres, assim como os solos, já se encontram com as suas capacidades de armazenamento parcial ou totalmente preenchidas pelas chuvas dos meses anteriores. Por outro lado, entre agosto a dezembro não há registros na séria analisada, situação esperada, pois se trata do período de estiagem (Gráfico 06). 


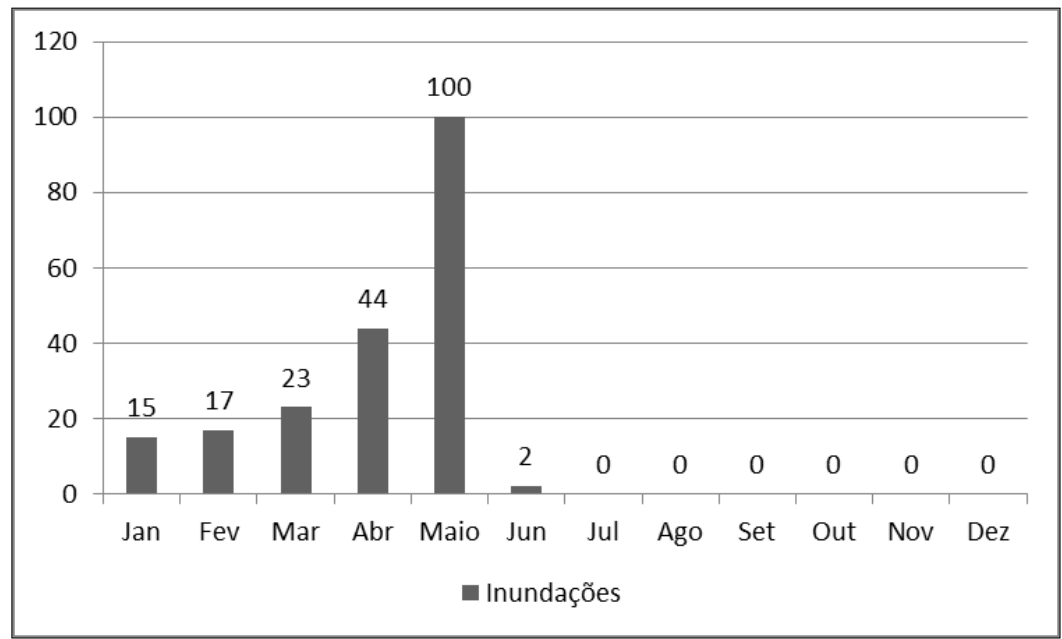

GRÁFICO 06: Distribuição mensal dos registros de AVADANs de inundações no estado do Ceará. Fonte: SEDEC (2003 / 2010).

Com relação às tipologias de uso e ocupação do solo afetadas, nota-se que os formulários indicam que os impactos foram mais frequentes nas áreas rurais do que nas urbanas (Gráfico 07).

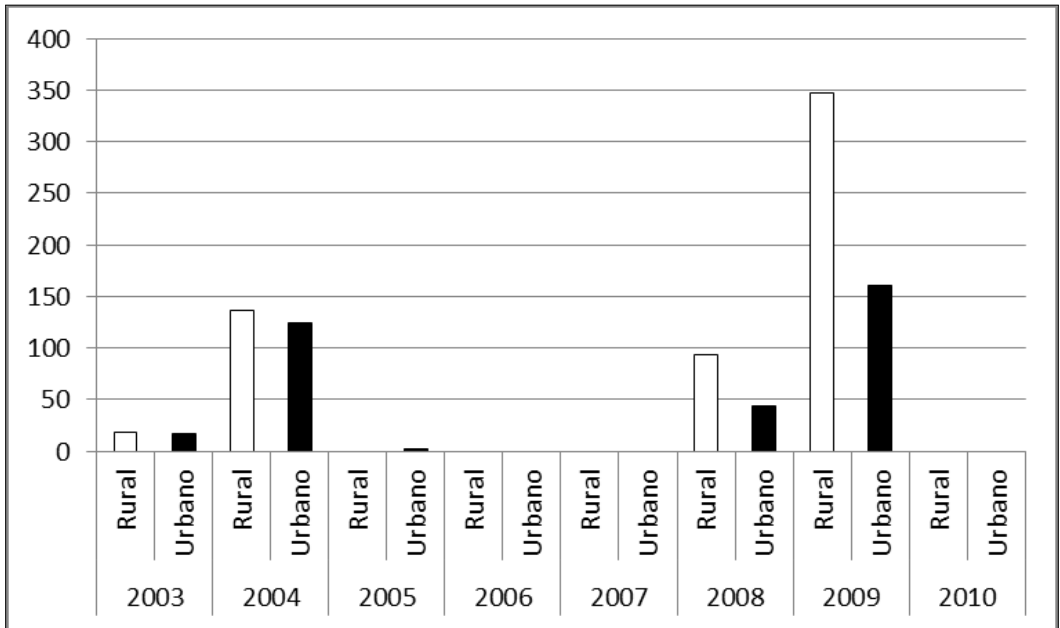

GRÁFICO 07: Distribuição mensal dos danos e prejuízos decorrentes das inundações entre as zonas rurais e urbanas

Fonte: SEDEC (2003 / 2010).

Observa-se que os impactos foram mais frequentes nos espaços rurais residenciais e agrícolas, seguidos pelas áreas urbanas residenciais e pelas áreas rurais turísticas. Os principais impactos foram às inundações das residências, comércios, prédios públicos e cultivos, além do comprometimento da estrutura viária e dos serviços de educação, saúde, abastecimento de água, coleta de resíduos sólidos e esgotamento sanitário (Tabela 06).

Diferente das estiagens, as inundações apresentam uma tipologia de danos humanos mais diversificada. Embora, a classe "Afetada" apresente a maior frequência $(79,8 \%)$, também foram registrados danos relacionados ao deslocamento de famílias que tiveram suas residências atingidas pelas inundações, seguida das tipologias "Desalojados" (7,1\%), "Desabrigadas" $(2,7 \%)$ e "Deslocadas" (1,1\%). 
TABELA 06: Tipologia dos usos rurais e urbanos afetados pelas inundações

\begin{tabular}{ccc}
\hline Tipo de Uso & Rural & Urbano \\
\hline Residencial & 164 & 160 \\
Comercial & 39 & 49 \\
Industrial & 15 & 18 \\
Agrícola & 162 & 22 \\
Pecuária & 65 & 17 \\
Extrativismo & 3 & 3 \\
Reserva Florestal & 5 & 5 \\
Mineração & 6 & 3 \\
Turismo e outras & 138 & 72 \\
\hline Fonte: SEDEC (2003 / 2010).
\end{tabular}

No que tange a distribuição espacial das pessoas atingidas pelas inundações, observa-se uma relativa concentração na bacia hidrográfica do rio Jaguaribe, destacando-se as sub-bacias do médio Jaguaribe, Salgado e Banabuiú. A cidade de Fortaleza também esteve entre as mais afetadas.

Quanto aos prejuízos econômicos, verificou-se que 81,0\% dos AVADANs relataram perdas na agricultura, $29,5 \%$ na pecuária, $7,5 \%$ nos serviços e $7,0 \%$ na indústria. Já os prejuízos sociais estiveram relacionados, principalmente, ao comprometimento dos serviços de saúde e de educação, seja porque as inundações causaram danos às estruturas dos prédios, seja devido ao uso destes como abrigo pelos atingidos.

Também foram registrados danos no abastecimento público, devido à contaminação das fontes hídricas que pelos excessos pluviais recebeu maiores contribuições de resíduos e efluentes. Além disso, foram informados prejuízos na coleta de lixo, no setor de transporte e no fornecimento de energia.

Posteriormente, foi analisada a intensidade dos prejuízos econômicos. Deste modo, as inundações ocasionaram prejuízos econômicos predominantemente de baixa importância, sendo que 65,0\% encontravam-se na classe "Média" e 11,5\% na "Pouco Importante". No entanto, $12,5 \%$ dos AVADANs relataram prejuízos de vulto "Importante" e 8,5\% "Muito Importante". Por fim, 2,5\% dos formulários não indicaram a intensidade dos prejuízos econômicos (Gráfico 08).

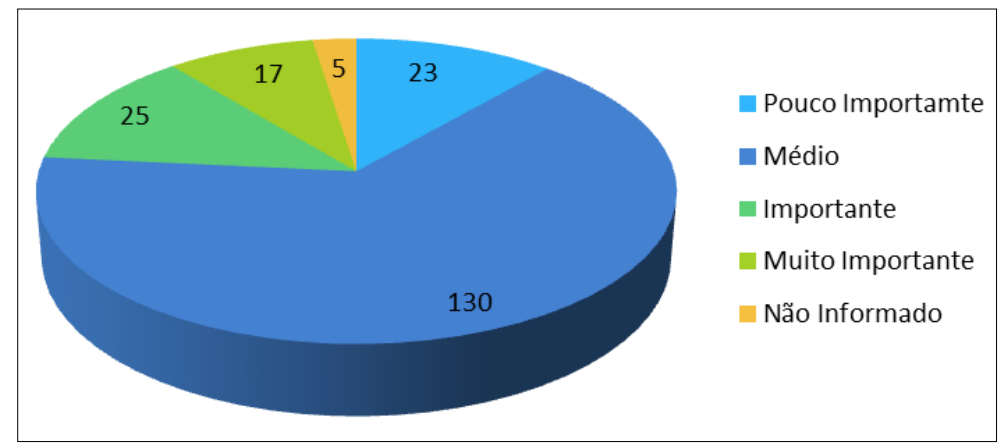

GRÁFICO 08: Intensidade dos prejuízos econômicos decorrentes de inundações Fonte: SEDEC (2003 / 2010). 


\section{CONCLUSÃO}

Conforme exposto, os fenômenos naturais das secas/estiagens e as inundações associados ao contexto social, econômico, cultural, institucional e estrutural são os fatores que induzem a formação de desastres naturais no estado do Ceará.

A variabilidade da pluviosidade da região semiárida é a principal fonte de eventos naturais adversos, ora promovendo a escassez hídrica, através dos fenômenos das secas e estiagens, ora ocorrendo desvios positivos geradores de episódios pluviais concentrados ou períodos chuvosos prolongados, que suscitam a desorganização do espaço geográfico, por meio das inundações.

No entanto, a constituição das crises está igualmente relacionada aos níveis de exposição, resistência e resiliência indutoras das vulnerabilidades dos grupos sociais e dos indivíduos residentes no estado do Ceará, fruto de um contexto social, econômico, estrutural, político e cultural presente neste território, mas que ocorre com maior intensidade sobre determinadas porções dos municípios, nas quais residem os indivíduos mais vulneráveis às manifestações dos eventos naturais adversos, revelando o quadro de segregação socioespacial e socioambiental existente nos espaços rurais e urbanos cearenses.

A partir do levantamento das Portarias de Reconhecimento de Situação de Emergência e Estado de Calamidade Pública, constatou-se que no referido território é frequente a ocorrência destes episódios adversos, sobretudo quando ocasionados pela escassez hídrica. Os principais danos e prejuízos ocorridos foram as perdas na agricultura e na pecuária e o desabastecimento dos núcleos populacionais.

Em seguida, as inundações foram os eventos mais significativos, ocorrendo com maior destaque nos anos de 2004, 2008 e 2009, períodos que tiveram precipitações acima das médias. Foram reconhecidas 255 Portarias, sendo que 11 eram relativas à decretação de ECP e 244 à SE. Os principais dados gerados também estiveram relacionados às atividades agrícola e pecuária, além de prejuízos nos serviços e infraestruturas públicas.

A gestão dos riscos de desastres naturais é uma atividade complexa, pois supõe um nível de sintonia entre todas as instancias, incluindo as próprias pessoas, frequentemente ausentes no processo de tomada de decisão, mas que se encontram no front no momento em que o desastre ocorre (HÉTU, 2003).

Neste contexto, vale ressaltar que a gestão dos riscos no Brasil ainda é bastante ineficiente, devido à priorização de ações de reconstrução após a crise instalada, e ainda assim, diante de um quadro de morosidade na destinação de recursos para auxilio dos municípios e na execução de projetos, causando transtornos incalculáveis aos vitimados. Além disso, observa-se um planejamento incompatível com a busca de soluções, uma vez que, normalmente, as ações empreendidas apenas objetivam o retorno às condições semelhantes ao cenário existente antes da crise.

Nestes termos, é necessária a realização de uma gestão dos riscos de desastres mais eficientes, a partir da participação de todos os agentes sociais envolvidos. Assim, faz emitente a elaboração de pesquisas visando o entendimento dos processos socioambientais reinantes no espaço geográfico, destacando-se aqueles onde o risco natural está presente. 
As pesquisas de desastres têm a função de apresentar e convencer a sociedade civil e o Poder Público da situação existente e apontar caminhos que devem ser traçados, cabendo aos demais agentes sociais refutarem ou aceitarem a problemática e construir os mecanismos que devem ser realizados para o alcance dos objetivos conforme suas escolhas e aspirações.

Por fim, enfatiza-se que a gestão deve ser um processo social pautado na discursão entre a população, gestores públicos, especialistas e os demais agentes, através da promoção de debates em e entre as diversas organizações sociais, pautadas sobre o fomento da inovação científica e da divulgação do conhecimento, fatores que podem tornar as sociedades mais preparadas e conscientes dos riscos presentes nos espaços que habitam.

\section{AGRADECIMENTOS}

Os autores agradecem à Fundação Cearense de Apoio ao Desenvolvimento Científico e Tecnológico (FUNCAP) pelo financiamento desta pesquisa.

\section{BIBLIOGRAFIA}

BRASIL. Decreto $n^{\circ} 7.257$, de 4 de agosto de 2010. Regulamenta a Medida Provisória $n^{\circ} 494$ de 2 de julho de 2010, para dispor sobre o Sistema Nacional de Defesa Civil - SINDEC, sobre o reconhecimento de situação de emergência e estado de calamidade pública, sobre as transferências de recursos para ações de socorro, assistência às vítimas, restabelecimento de serviços essenciais e reconstrução nas áreas atingidas por desastre, e dá outras providências. Diário Oficial da União, DF, 6 de ago. de 2010.

CASTRO, A. L. C; CALHEIROS, L. G; MOURA, A. Z. B. Glossário de Defesa Civil Estudos de Riscos e Medicina de Desastres. Brasília: MIN, 5 ed., 2004.

CASTRO, C. M; PEIXOTO, M. N. O; DO RIO, G. A. P. Riscos ambientais e geografia: conceituações, abordagens e escalas. Anuário do Instituto de Geociências, Rio de Janeiro, v. 28, n. 2, p. 11-30, 2005.

CLIMATE PREDICTION CENTER - CPC. Cold and warm episodes by season. Disponível em $<w w w . c p c . n c e p . n o a a . g o v / p r o d u c t s / a n a l y s i s \_m o n i t o r i n g / e n s o s t u f f / e n s o y e a r s . s h t m l>$.

Acessado em: out., 2012

FERREIRA, A. G.; MELLO, N. G. S. Principais sistemas atmosféricos atuantes sobre a região nordeste do Brasil e a influência dos oceanos pacífico e atlântico no clima da região. Revista Brasileira de Climatologia, v. 1, n. 1, 2005.

HÉTU, B. Uma Geomorfologia socialmente útil: os riscos naturais em evidência. Revista Mercator. Fortaleza, ano 2, n. 3, 2003.

KOBIYAMA, M; MENDOÇA, M; MARCELINO, I. P. V. O; MARCELINO, E. V; GONÇALVES, E. F; BRAZETTI, L. L. P; GOERL, R. F; MOLLERI, G. S. F; RUDORFF, F. M; MOLLERI, G. S. F. Prevenção de Desastres Naturais: conceitos básicos. Florianópolis: Organic Trading, 2006.

INTERNATIONAL STRATEGY FOR DISASTER REDUCTION - ISDR. Living with risk: a global review of disaster reduction initiatives. Geneva: UN/ISDR, 2004.

MARCELINO, E. V. Desastres Naturais e Geotecnologias: conceitos básicos. Caderno Didático no 1. São José do Campus, INPE, 2008. 
MELLO, A. B. C; CAVALCANTI, I. F. A; SOUZA, P. P. Zona de Convergência Intertropical do Atlântico. In: CAVALCANTI, I. F. A. C; FERREIRA, N; SILVA, M. G. A. J; DIAS, M. A. S. (Orgs). Tempo e Clima no Brasil. São Paulo: Oficina de textos, 2009.

MENDONÇA, F. Geografia e Meio Ambiente. São Paulo: Contexto, 2005.

MONTEIRO, J. B. Chover, mas chover de mansinho: desastres naturais e chuvas extremas no Estado do Ceará. Fortaleza: UECE, 2011, 198p. Dissertação de Mestrado - Programa de PósGraduação em Geografia, Universidade Estadual do Ceará, Fortaleza, 2011.

OLíMPIO, J. L. S. Desastres naturais associados à dinâmica climática no Estado do Ceará: subsídios à gestão dos riscos de secas e de inundações. Fortaleza: UFC, 2013, 226p. Dissertação de Mestrado - Programa de Pós-Graduação em Geografia, Universidade Federal do Ceará, Fortaleza, 2013.

OLIVEIRA, V. P. V. A problemática da Degradação dos recursos naturais no domínio dos sertões secos do Estado do Ceará-Brasil. In: SILVA, J. B; DANTAS, E. W. C; ZANELLA, M. E; MEIRELES, A. J. A. (Org.). Litoral e Sertão: natureza e sociedade no nordeste brasileiro. Fortaleza: Expressão Gráfica, 2006.

PINHEIRO, A. Enchente e Inundação. In: SANTOS, R. F (Org.) Vulnerabilidade Ambiental: desastres naturais ou fenômenos induzidos. Brasília: MMA, 2007

REBELO, F. Um novo olhar sobre os riscos? O exemplo das cheias rápidas (Flash Floods) em domínio mediterrâneo. Territorium, v. 15, p. 7-14, 2008.

SECRETARIA NACIONAL DE PROTEÇÃO E DEFESA CIVIL - SEDEC. Disponível em $<$ http://s2id.mi.gov.br/>. Acessado em: mar. 2013.

SOUZA, L. B; ZANELLA, M. E. Percepções de Riscos Ambientais: teorias e aplicações. Fortaleza: Edições UFC, 2009.

UVO, C. R. B. A Zona de Convergência Intertropical (ZCIT) e sua relação com norte do Nordeste Brasileiro. São José dos Campos: INPE, 1989, 82p. Dissertação de Mestrado Programa de Pós-graduação em Meteorologia, Instituto Nacional de Pesquisa Espaciais, São José dos Campos, 1989.

VEYRET, Y; RICHMOND, N. M. O risco, os riscos, In: VEYTET, Y (Org.). Os riscos: o homem como agressor e vítima do meio ambiente. São Paulo: Contexto, 2007.

ZANELLA, M. E. Considerações sobre o clima e os recursos hídricos do semiárido nordestino. Caderno Prudentino de Geografia, Presidente Prudente, SP, p. 126-142, 2014.

\begin{tabular}{|l|l|}
\hline Artigo submetido em & $03 / 07 / 2015$ \\
\hline Artigo aceito em & $18 / 09 / 2015$ \\
\hline
\end{tabular}

